\title{
Gelatin Coating on Quality Attributes of Sausage during Refrigerated Storage
}

\author{
Jinhan Shon, Ji-Hyun Eo ${ }^{1}$, and Yong-Hwa Choi* \\ Daegu Gyeongbuk Institute for Korea Traditional Medicine Industry, Gyeongsan 712-260, Korea \\ ${ }^{1}$ Department of Food Science and Technology, Chonnam National University, Gwangju 500-757, Korea \\ ${ }^{2}$ College of Ecological and Environmental Science, Kyungpook National University, Sangju 742-711, Korea
}

\begin{abstract}
Gelatin-based edible coating was used to reduce the oxidative degradation of low-fat sausages (LFSs) stored at $4^{\circ} \mathrm{C}$ for 8 wk under vacuum packaging. The gelatin coating reduced thiobarbituric acid-reactive substances and peroxide value by 21.5 and $26.5 \%$, respectively, compared with the controls. The moisture barrier effect was significantly better for the gelatin coating compared to the control. The gelatin coating reduced moisture loss in sausages by $32.6 \%$ over the control. However, the gelatin coating of sausages did not inhibit the growth of either the total plate counts or L. monocytogenes. Data show that gelatin can effectively be used as a natural antioxidative and moisture barrier coating to extend the quality and shelf life of sausages.
\end{abstract}

Key words: gelatin coating, sausage, lipid oxidation, moisture barrier, shelf life

\section{Introduction}

Modern trends in convenience foods have resulted in the increased consumption of precooked, refrigerated, or frozen ready-to-eat (RTE) meats and meat products such as sausages and hams due to not only their nutritional values but also their taste and flavor. However, these products are particularly susceptible to lipid oxidation, which leads to the rapid development of warmed-over flavor during storage (Love, 1988). Lipid oxidation results in off-flavors and odors, loss of polyunsaturated fatty acids, fat-soluble vitamins and pigments and reduced consumer acceptability (Gray et al., 1987). Various synthetic antioxidants, such as butylated hydroxytoluene (BHT) and butylated hydroxyanisole (BHA), are commonly used to minimize lipid oxidation of food systems (Decker, 1998). However, these synthetic antioxidants have been limited in their applications as food additives by consumers due to health concern, and preferably nonchemical and natural. Synthetic antioxidants have been shown to cause lesion formation in the rat forestomach and internal and

\footnotetext{
*Corresponding author: Yong-Hwa Choi, College of Ecological \& Environmental Science, Kyungpook National University, Sangju 742-711, Korea. Tel: 82-54-530-1201, Fax: 82-54-5301209, E-mail: ychoi@knu.ac.kr
}

external haemorrhaging in some strains of mice and guinea pig at high dose (Shahidi and Wanasundara, 1992). Thus, there is motivation to search for safe and natural antioxidants from various sources originating from sea foods.

Gelatin is a protein resulting from partial hydrolysis of collagen using acid or alkali treatment followed by or accompanied with heating in the presence of water (Liu et al., 2008). The principal raw materials used for gelatin manufacture are pork skins and bovine hides, skins and bones (Liu et al., 2008). Recently attention has focused on the properties of films or coatings made from fish gelatins (Avena-Bustillos et al., 2006). Enzymatic processing is an alternative to acid or alkali hydrolysis for conversion of collagen to gelatin producing a higher purity, better physical properties, and a narrower molecular weight distribution (Hinterwaldner, 1977).

Research interest in edible coatings made from proteins, polysaccharides and lipids has intensified in recent years. These coatings can help maintain and improve the quality of fresh, frozen and processed muscle foods by reducing moisture loss, lipid oxidation and color deterioration, act as carriers for antimicrobial and antioxidant food additives (Gennadios et al., 1997).

Gelatin has been used as a preservative coating for meat and other foods (Villegas et al., 1999). Gelatin coatings or films have also been used to carry antimicrobials 
and antioxidants. The antioxidative activity of proteins is due to complex interactions between their ability to inactivate reactive oxygen species, scavenging free radicals, chelatate prooxidative transition metals (Elias et al., 2008). Previous reports demonstrated that gelatin coatings derived from fish sources effectively inhibited lipid oxidation in cooked ham and bacon (Villegas et al., 1999), in turkey steaks (Klose et al., 1952), and in cut pork belly (Marggrander and Hofmann, 1997). However, sufficient information about antioxidative and microbiological characteristics of edible gelatin coatings or films from fish sources is not available in literature. The objective of this study was to investigate the effect of gelatin coating would delay the progress of lipid oxidation and preserve color and moisture in cut low-fat sausages (LFSs) during refrigerated storage for $8 \mathrm{wk}$.

\section{Materials and Methods}

\section{Materials}

Skate skins used in the present study were obtained from a local skate processing plant (Korea). Glycerol, calcium chloride, carboxymethyl cellulose (CMC), trichloroacetic acid, 2-thiobarbituric acid, methanol, ammonium thiocyanate, and ferrous chloride were all from Sigma Co. (USA). Glycerol and calcium chloride were food grade. Isooctane, 2-propanol, 1-butanol, hydrochloric acid, and barium sulfate were from Fisher Scientific (USA). L. monocytogenes strain (ATCC, 43256) was obtained from the American Type Culture Collection (USA) and palcam agar base was obtained from Oxoid Ltd. (England). Plate count agar was obtained from Difco Laboratories (USA). All other reagents were analytical grade.

\section{Manufacture of gelatin}

The extraction procedures of gelatin from skate skins are described by Shon et al. (2011). The skate skins were thoroughly washed with tap water to remove impurities. The cleaned skate skins were soaked with a $0.1 \mathrm{~N} \mathrm{NaOH}$ solution, followed by washing with deionized distilled water (DDW) to remove alkali. The gelatin extraction was carried out in DDW at $50^{\circ} \mathrm{C}$ overnight. The extracts were centrifuged at $15,000 \mathrm{~g}$ for $1 \mathrm{~h}$ at $4^{\circ} \mathrm{C}$ and the supernatants were immediately collected. The aliquots of the extract were then filtered through Whatman No.1 filter paper and activated carbon (250-350 mesh) and lyophilized to obtain gelatin powder. Gelatin samples were stored in sealed containers at $-20^{\circ} \mathrm{C}$ until needed.

\section{Manufacture of low-fat sausages (LFSs)}

The LFSs were manufactured as described by Shon and Chin (2008). Fresh pork hams, from pigs which had been slaughtered a day earlier, were purchased from a local retail meat market, and all visible fats and connective tissues were removed. Trimmed pork hams were ground, vacuum-packaged, and stored at $-20^{\circ} \mathrm{C}$ prior to use. Frozen pork hams were thawed and chopped to reduce the particle size. Salt, sodium nitrite, sodium erythorbate, and half of ice water were then added and chopped for $2 \mathrm{~min}$ to extract the salt soluble proteins. Seasonings, flavorants, and the remaining ice water were then added, and the meat batter was chopped until the temperature reached 15 to $16^{\circ} \mathrm{C}$. Formulation and non-meat ingredients incorporated into LFSs for this study are listed in Table 1 . The meat batter was vacuum-packaged and stuffed into cellulose casing (Suntan, Viscase Crop., USA), smoked, and cooked to an internal temperature of $71.7^{\circ} \mathrm{C}$ in a smoke chamber (Nu-Vu, ES-13, Food System, USA). After cooking, the sausages were chilled immediately in an ice bath and cut (about $20 \mathrm{~cm}$ ) and vacuum-packaged in oxygen permeable $\left(45 \mathrm{~mL} / \mathrm{m}^{-2} / 24 \mathrm{~h}\right)$ with vacuum film (200 x 300 mm, Fuji Plant Korea Inc., Korea), and stored in a refrigerator $\left(4^{\circ} \mathrm{C}\right)$ for $8 \mathrm{wk}$.

\section{Preparation of gelatin coating solution}

The edible coating solution of gelatin was prepared as described by Shon et al. (2010). A 5\%(w/v) aqueous solution of gelatin was prepared. Sorbitol $(2.5 \%, \mathrm{w} / \mathrm{v})$, $\mathrm{CaCl}_{2}(0.125 \%$, w/v), and $\mathrm{CMC}(0.25 \%$, w/v) were added

Table 1. Formulation of meat and non-meat ingredients incorporated into low-fat sausage

\begin{tabular}{lc}
\hline \multicolumn{1}{c}{ Ingredients } & Amounts (\%) \\
\hline Pork (hams) & 55.0 \\
Ice water $^{\text {Non-meat ingredients }}$ & 35.1 \\
- Fat replacers ${ }^{\mathrm{a}}$ & 9.90 \\
- Salt & 2.50 \\
- Sugar & 1.25 \\
- Corn syrup & 1.00 \\
- Sodium tripolyphosphate & 1.00 \\
- Non-fat dry milk & 0.30 \\
- Maltodextrin & 1.00 \\
- Hydrolyzed milk protein & 1.00 \\
- Frankfurter spices & 0.50 \\
- Sodium erythorbate & 1.00 \\
- Salt/Sodium nitrite (Cure blend) & 0.05 \\
\multicolumn{2}{c}{ Total (\%) } \\
\hline
\end{tabular}

${ }^{\mathrm{a}}$ Fat replacers: konjac flour, carrageenan, and soy protein isolate at the ratio of $1: 1: 3$. 
in DDW with constant vortexing, followed by degassing under vacuum. Subsequently, the solution was heated at $90^{\circ} \mathrm{C}$ for $30 \mathrm{~min}$ in a shaking water bath. The solution was homogenized for $2 \mathrm{~min}$ in a high-shear probe mixer (Hamilton Beach, USA) and filtered through a layer of cheese cloth to ensure the complete mixing of the lipid components and to remove foam and undissolved materials. The solution was cooled at room temperature (22 \pm $1^{\circ} \mathrm{C}$ ) and degassed again with a vacuum pump. The final $\mathrm{pH}$ of the solution was adjusted to 6.5 with $0.1 \mathrm{M}$ and/or $1.0 \mathrm{M} \mathrm{HCl}$ or $\mathrm{NaOH}$, and the solution was stored at $2^{\circ} \mathrm{C}$ to allow the viscosity to increase before use.

Fresh LFSs slices $\left(2.5 \mathrm{~cm}^{3}\right)$ were cut from three different sausages for each treatment for each analysis. The sausage slices were randomly assigned for control and coating treatment. The sausage slices were dipped into the gelatin coating solution for $1 \mathrm{~min}$ at room temperature $\left(22 \pm 1^{\circ} \mathrm{C}\right)$ and drained for $10 \mathrm{~s}$. The sausage slices were then dried under a laminar hood with blowing clean air flow for $2 \min \left(22 \pm 1^{\circ} \mathrm{C}\right)$. The sausages were vacuumpackaged immediately using vacuum films $(200 \times 300$ $\mathrm{mm})$ and stored in a refrigerator $\left(4^{\circ} \mathrm{C}\right)$ for up to $8 \mathrm{wk}$ for analysis. Control samples were dipped in DDW instead of gelatin coating solution and the process of drying was the same as that for the treatments.

\section{Proximate analysis and $\mathrm{pH}$ values}

Moisture, fat, and protein contents were determined in triplicate by AOAC (1990). A pH meter (MP120, Mettler Toledo, Switzerland) was used for the $\mathrm{pH}$ measurement of the LFSs. Ten grams of sausage slices were homogenized with $90 \mathrm{~mL}$ of DDW for $30 \mathrm{~s}$ using a Biomixer (Hamilton Beach, USA) and $\mathrm{pH}$ values were measured in triplicate.

\section{Color measurements}

Color values were measured using a Chroma meter (CR-200, Minolta Corp., USA), which was standardized using as white blank $\left(\mathrm{L}^{*}=91.1, \mathrm{a}^{*}=1.28, \mathrm{~b}^{*}=-1.54\right)$. Samples were placed on a transparent glass plate and five readings on different sites of each sausage sample were averaged for color measurement of on sample. The results were expresses as Hunter L* (lightness), a* (redness), and $b^{*}$ (yellowness) color scale.

\section{Measurements of antioxidative activity}

Thiobarbituric acid-reactive substances (TBARS) Inhibition of oxidation in LFSs was determined as described by Shon et al. (2010). Coated and uncoated sausages $(20 \mathrm{~g})$ were homogenized with DDW $(50 \mathrm{~mL})$ using a Biomixer (Hamilton Beach, USA) for 2 min. Sausages homogenate $(2 \mathrm{~mL})$ was transferred to a centrifuge tube and $2 \mathrm{~mL}$ of TBA reagent (15\% trichloroacetic acid (w/v) and $0.375 \%$ 2-thiobarbituric acid (w/v) in $0.25 \mathrm{M}$ $\mathrm{HCl}$ were added. The solution was then heated in a $100^{\circ} \mathrm{C}$ water bath for $15 \mathrm{~min}$ and cooled in an ice bath for 10 $\min$. The resulting mixture was centrifuged at $6,000 \mathrm{~g}$ for $5 \min \left(22 \pm 1^{\circ} \mathrm{C}\right)$, the supernatant was collected and the absorbance was measured at $532 \mathrm{~nm}$ using a UV-visible spectrophotometer (Shimadzu Co., Japan). The percent inhibition (PI) was recorded as following:

$$
\begin{aligned}
\mathrm{PI}= & 1-[(\text { TBARS }(\mathrm{mg} \mathrm{MDA} / \mathrm{kg} \text { of gelatin coated sausage }) \\
& /(\text { TBARS }(\mathrm{mg} \text { MDA } / \mathrm{kg} \text { of uncoated control sausage })] \\
& \times 100
\end{aligned}
$$

\section{Peroxide value (PV)}

A modified ferric thiocyanate (FTC) method as described by Shon et al. (13) was used to evaluate the effect of gelatin coating on hydroperoxide formation in LFSs. Coated and uncoated sausage samples $(20 \mathrm{~g})$ were homogenized with DDW $(50 \mathrm{~mL})$ using a Biomixer for $2 \mathrm{~min}$. A $2 \mathrm{~mL}$ aliquot was vortexed ( $10 \mathrm{~s}, 3$ times) with $3 \mathrm{~mL}$ of isooctane/2-propanol (3:1, v/v) and centrifuged at 2,000 $\mathrm{g}$ for 5 $\min \left(22^{\circ} \mathrm{C}\right)$ to obtain the organic solvent phase. An aliquot of this phase $(400 \mu \mathrm{L})$ was added to $3 \mathrm{~mL}$ of methanol/1-butanol $(2: 1, \mathrm{v} / \mathrm{v})$, followed by $30 \mu \mathrm{L}$ of $30 \%$ ammonium thiocyanate and $30 \mu \mathrm{L}$ of the ferrous chloride solution. The absorbance of the solution was measured at $500 \mathrm{~nm}$ using a UV-visible spectrophotometer for $20 \mathrm{~min}$ after addition of the ferrous chloride solution. The PI was calculated using the same formula that was used for calculating TBARS.

\section{Percent moisture loss (PML)}

The PML was determined as described by Shon et al. (2010). The moisture content (MC, wet basis) of the samples was determined and calculated using the AOAC method (AOAC) (1990). Triplicate samples (about $5 \mathrm{~g}$ ) were oven (Dasol Scientific Co. Ltd., Korea) dried at $102^{\circ} \mathrm{C}$ for $18 \mathrm{~h}$. The samples were then cooled in a desiccator (Dongsung Glass Co. Ltd., Korea) to room temperature and reweighed (Mettler Toledo Group, Switzerland). The MC of all samples was determined before (wk 0 ) and after storage for $8 \mathrm{wk}$ at $4^{\circ} \mathrm{C}$. The PML was calculated as:

$$
\text { PML }(\%)=[(\text { initial MC final MC }) / \text { initial MC }] \times 100
$$


Inoculation of Listeria monocytogenes and coating of sausage samples

The sausages were inoculated and coated using the modified procedure outlined by Shon et al. (2010). To prepare the inoculation, an aliquot of $L$. monocytogenes strain (ATCC, 43256) was placed in $9 \mathrm{~mL}$ of palcam agar base (PAB) with $1 \mathrm{~mL}$ being transferred to a fresh $9 \mathrm{~mL}$ $\mathrm{PAB}$ and incubated for $24 \mathrm{~h}$ at $37^{\circ} \mathrm{C}$. Several dilutions were then prepared in sterilized water to obtain a final concentration of $10^{6}$ colony CFU/g of sausage. Fresh sausage samples were cut ( $25 \mathrm{~g})$ and individually dipped for $1 \mathrm{~min}$ into culture broth containing approximately $10^{6}$ CFU/g of L. monocytogenes. Sausages were removed from the culture broth and allowed to drip free of excess inoculum and dry for 30 min under a laminar hood with blowing air. Sausage samples were coated with the gelatin film-forming solution by dipping them in it for $1 \mathrm{~min}$ and allowing them to drip dry. Control consisted of inoculated sausage slices without any gelatin coating. After inoculation and coating, the sausage samples were packaged immediately using sterile vacuum films $(200 \times 300$ $\mathrm{mm})$, and stored for up to $8 \mathrm{wk}$ in a re- frigerator $\left(4^{\circ} \mathrm{C}\right)$ for analysis. Control and gelatin coated sausages were subjected to a temperature of $4^{\circ} \mathrm{C}$. The total aerobic bacteria (TPC) and L. monocytogenes on the control and gelatin-coated sausage samples were counted over the 8 wk experimental storage period. Sausage samples (25 g) inoculated with $10^{3} \mathrm{CFU} / \mathrm{g}$ of L. monocytogenes were homogenized in $225 \mathrm{~mL}$ of sterilized DDW. The mixtures were plated on a plate counts agar for TPC and on palcam agar for L. monocytogenes. Colonies were counted after incubation at $37^{\circ} \mathrm{C}$ for $48 \mathrm{~h}$ and results were expressed as $\log _{10} \mathrm{CFU} / \mathrm{g}$.

\section{Statistical analysis}

The experiment was performed in triplicate and data were analyzed using a 2 (treatments) $\times 6$ (storage times, $0,1,2,4,6$, and $8 \mathrm{wk}$ ) factorial design using the general linear model (PROC GLM) procedure of a SAS Statistical Program 8.1 (SAS, 2001). Means were separated using Fisher's protected least significance test $(p<0.05)$.

\section{Results and Discussion}

\section{Proximate analysis}

The mean values of LFSs of moisture, crude fat, and crude protein content $(\%)$ were $76.2 \pm 1.11,0.33 \pm 0.02$, and $13.7 \% \pm 0.06$, respectively (data not shown).

\section{pH values}

Since no interactions $(p>0.05)$ were observed between treatment and storage time for $\mathrm{pH}$ and Hunter $\mathrm{L}^{*}, \mathrm{a}^{*}$ and $b^{*}$ values of sausages, data were pooled and are shown in Table 2. The initial $\mathrm{pH}$ decreased from $6.11 \pm 0.03$ to 5.29 \pm 0.07 for the LFSs during refrigerated storage (Table 2). Thus, the storage time had a significant effect on $\mathrm{pH}$ at the 4-wk of storage $(p<0.05)$, but gelatin coating did not affect the $\mathrm{pH}(p>0.05)$. The $\mathrm{pH}$ values were quite stable until the $2 \mathrm{wk}$ of storage and then decreased thereafter $(p$ $<0.05$ ). These results mean that sausages started to spoil after the $2 \mathrm{wk}$ of storage. The reduction in $\mathrm{pH}$ was due to formation of lactic acid by lactic acid bacteria that utilized carbohydrate added in the formulation as an energy source (Antara et al., 2004).

\section{Color measurements}

Hunter color $\mathrm{L}^{*}$ value (lightness) was not affected by the gelatin coating. The colorimetric $\mathrm{L}$ value decreased from $68.1 \pm 0.69$ to $65.8 \pm 0.64$ during refrigerated storage (Table 2) due to the browning reaction (Papastamatiou et al., 2007). No differences in lightness were found between the control and gelatin coated sausages under vacuum

Table 2. pH and Hunter color values of sausages with gelatin-based edible coating during storage at $4^{\circ} \mathrm{C}$ for 8 wk under vacuum package $^{1)}$

\begin{tabular}{|c|c|c|c|c|c|c|c|c|}
\hline & \multicolumn{2}{|c|}{ Treatments } & \multicolumn{6}{|c|}{ Storage time (wk) } \\
\hline & Control & Gelatin & 0 & 1 & 2 & 4 & 6 & 8 \\
\hline $\mathrm{pH}$ & $5.78 \pm 0.38^{\text {N.S }}$ & $5.80 \pm 0.36^{\text {N.S }}$ & $6.11 \pm 0.03^{\mathrm{a}}$ & $6.13 \pm 0.06^{\mathrm{a}}$ & $6.14 \pm 0.04^{\mathrm{a}}$ & $5.65 \pm 0.04^{b}$ & $5.32 \pm 0.04^{c}$ & $5.29 \pm 0.07^{\mathrm{c}}$ \\
\hline $\mathrm{L}^{*}$ & $66.8 \pm 0.91^{\text {N.S }}$ & $67.0 \pm 0.68^{\mathrm{N} . \mathrm{S}}$ & $68.1 \pm 0.69^{\mathrm{a}}$ & $67.7 \pm 0.27^{\mathrm{b}}$ & $66.4 \pm 0.45^{\mathrm{c}}$ & $67.2 \pm 0.34^{\mathrm{b}}$ & $66.2 \pm 0.40^{\mathrm{c}}$ & $65.8 \pm 0.64^{\mathrm{d}}$ \\
\hline$a^{*}$ & $12.3 \pm 0.40^{\mathrm{N} . \mathrm{S}}$ & $12.6 \pm 0.53^{\mathrm{N} . \mathrm{S}}$ & $11.9 \pm 0.37^{\mathrm{c}}$ & $12.4 \pm 0.46^{\mathrm{b}}$ & $13.2 \pm 0.23^{\mathrm{a}}$ & $12.5 \pm 0.40^{\mathrm{b}}$ & $12.4 \pm 0.45^{\mathrm{b}}$ & $12.3 \pm 0.31^{\mathrm{b}}$ \\
\hline$b^{*}$ & $8.51 \pm 0.38^{\mathrm{N} . \mathrm{S}}$ & $8.41 \pm 0.34^{\text {N.S }}$ & $7.97 \pm 0.42^{\mathrm{d}}$ & $8.17 \pm 0.51^{\mathrm{c}}$ & $8.42 \pm 0.54^{\mathrm{bc}}$ & $8.56 \pm 0.43^{b}$ & $8.68 \pm 0.47^{\mathrm{ab}}$ & $8.97 \pm 0.34^{\mathrm{a}}$ \\
\hline
\end{tabular}

\footnotetext{
${ }^{1)}$ Values represent means of 5 replications \pm SD.

N.S. $=$ nonsignificant

${ }^{\mathrm{a}-\mathrm{d}}$ Means within the same row with different superscripts are significantly different $(p<0.05)$.

$\mathrm{L}^{*}, \mathrm{a}^{*}$, and $\mathrm{b}^{*}$ are Hunter color values as determined by the colorimeter.

Control $=$ uncoated sausage; Gelatin $=$ gelatin coated sausage
} 
package $(p>0.05)$ (Table 2).

The other relevant part of the Hunter a* value (redness), which has been used as an indicator of color stability in meat and meat products, was not affected by the gelatin coating (Table 2). Hunter a* values of the sausage started $11.9 \pm 0.37$ at the beginning of storage and increased to $13.2 \pm 0.23$ at the 2 -wk of storage, but tended to decrease by the end of the storage period due to the denaturation of nitrosomyoglobin (Table 2). The rate of meat discoloration is related to the rate of myoglobin oxidation induced by lipid oxidation (Yin and Faustman, 1993). Gelatin coating, however, was effective ingredient in improving meat redness in cooked ham and bacon in both aerobic and vacuum packaging (Villegas et al., 1999).

The Hunter $b^{*}$ value, which contributes to the appearance of freshness, increased from $7.97 \pm 0.42$ to $8.97 \pm 0.34$ during refrigerated storage (Table 2). These results indicated that the sausages turned a yellow color with increased time. The color change might be mainly due to the lipid oxidation. However, this mechanism might not be fully understood. The relationship between lipid oxidation and metmyoglobin formation is that increases in redox potential during lipid oxidation tend to oxidize myoglobin (Hur et al., 2004). A previous report found an increase in yellowness due to rancidity during storage of vacuum packaged ham slices (Garcia-Esteban et al., 2004). No differences in yellowness were observed between control and gelatin-coated sausages under vacuum package $(p>0.05)$ (Table 2). Color stability is an important quality attribute contributing to meat shelf-life, texture, and consumer acceptability. Calcium chloride, a divalent salt, is incorporated into the coating solution to improve the texture and color of food products (Garcia-Esteban et al., 2001). Whey and soy protein coatings containing calcium chloride were effective in maintaining the reddish color characteristic of cut pork and beef steak (Shon et al., 2010; Haque et al., 2009), and controlled darkening and oxidative browning of fresh-cut fruit and vegetables (Park et al., 2001; Shon and Haque, 2007). Previous reports indicate that edible protein films containing $\mathrm{CaCl}_{2}$, which is as a crosslinking agent, have the potential for improved the mechanical properties (Park et al., 2001).

\section{Antioxidative activity}

The TBARS values for control and gelatin-coated sausages over the $8 \mathrm{wk}$ of storage periods at $4^{\circ} \mathrm{C}$ under vacuum package were comparable to the PV patterns (Fig. 1A). Control sausages had higher TBARS formation than the gelatin-coated sausages over the $8 \mathrm{wk}$ of storage peri- ods. The TBARS formation significantly $(p<0.05)$ increased up to $6 \mathrm{wk}$ of storage, indicating that lipid oxidation had occurred in sausages and then decreased thereafter. A decrease in TBARS values after $6 \mathrm{wk}$ of storage could be due to the formed TBARS being lost by further reaction. This decrease could also be attributed to decomposition of malonaldehyde (MDA) by bacteria, such as Pseudomonas and Enterobacteriaceae, which obtained the ability to selectively attack and utilize carbonyl compounds, including MDA (Moerck and Ball, 1974). The TBARS formation for gelatin-coated sausages were reduced compared to the control (Fig. 1B). There was significant inhibition of TBARS formation by $21.5 \%$ compared to the control for gelatin coating after $8 \mathrm{wk}$ of refrigerated storage under vacuumed packaging $(p<0.05)$ (Fig. 1B). Previous reports indicated that gelatin coating effectively inhibited lipid oxidation in cooked ham and bacon (Villegas et al., 1999), in turkey steaks (Klose et al., 1952), and
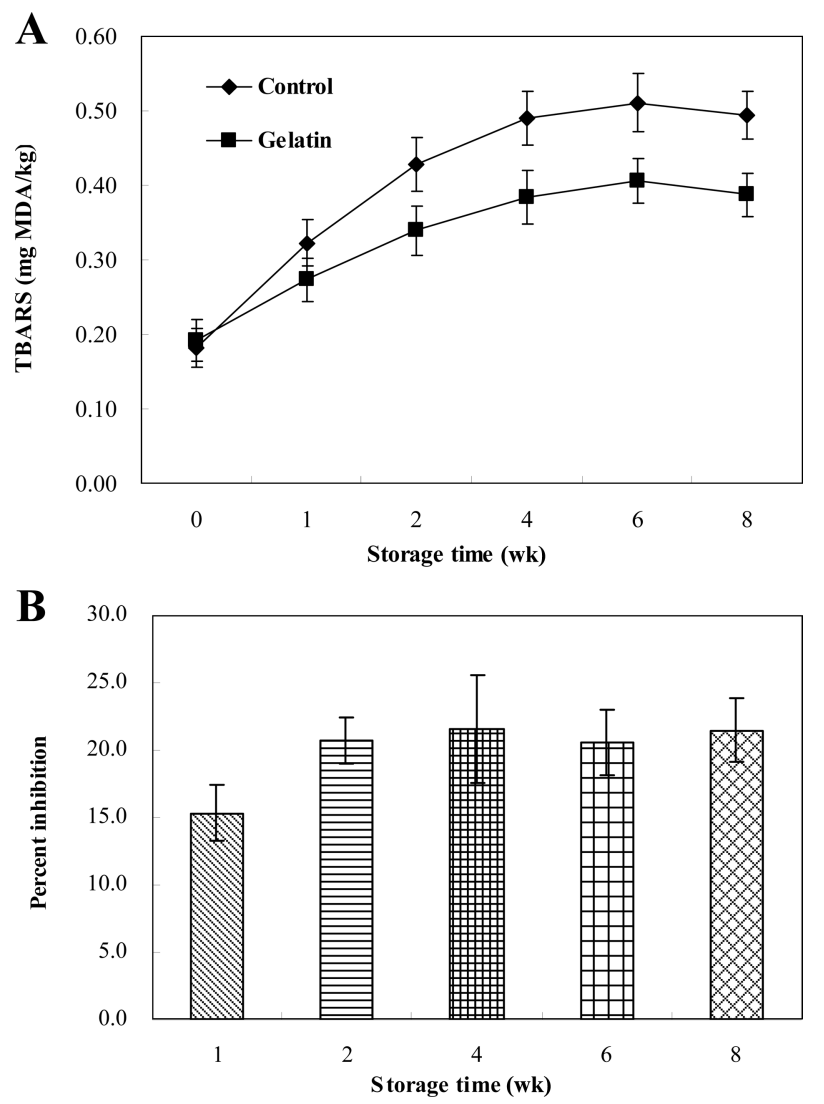

Fig. 1. (A) Changes in thiobarbituric acid-reactive substances (TBARS) (mg MDA/kg) formation in sausages with gelatin-based edible coating during storage at $4^{\circ} \mathrm{C}$ for 8 wk under vacuum package. (B) Percentage inhibition by gelatin coating on formation of TBARS in sausages after 8 wh of storage at $4^{\circ} \mathrm{C}$ under vacuum package. Control, uncoated sausage; gelatin, gelatin-coated sausage 
in cut pork belly (Marggrander and Hofmann, 1997), and improved retention of flavor, taste and aroma of cut pork belly during storage (Marggrander and Hofmann, 1997). This may be attributed to the good oxygen barrier properties of gelatin films or coatings (Krochta and De MulderJohnston, 1997). Our data suggest that these oxygen barrier properties can help reduce lipid oxidation and color deterioration during refrigerated storage of meat products.

The PVs for the control and gelatin-coated sausages increased continuously as storage time increased up to the 6-wk of refrigerated storage and then decreased thereafter (Fig. 2A). It is possible that the rate of hydroperoxide decomposition was higher than the rate of its formation (Georgantelis et al., 2007). As the refrigerated storage time increased, the PV also increased, however, the gelatin-coated sausages had a lower PV than the controls. Treatment with gelatin coating decreased PV formation
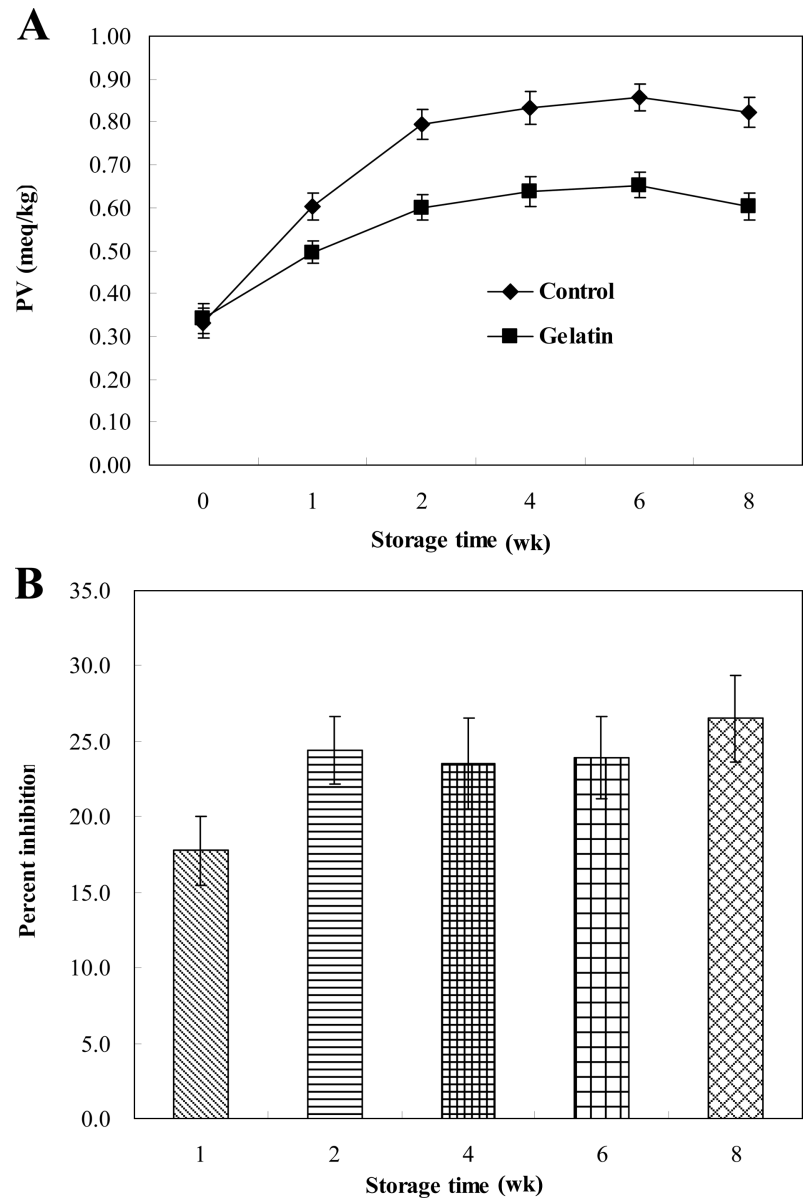

Fig. 2. (A) Changes in peroxide values (PV) (meq/kg) in sausages with gelatin-based edible coating during storage at $4^{\circ} \mathrm{C}$ for 8 wk under vacuum package. (B) Percentage inhibition by gelatin coating on $\mathrm{PV}$ in sausages after 8 wk of storage at $4^{\circ} \mathrm{C}$ under vacuum package. Control, uncoated sausage; gelatin, gelatin-coated sausage by more than $26.5 \%$ over the storage period $(p<0.05)$ (Fig. 2B). The CMC was incorporated into coating solution, and the carboxylic groups, which act as a chelating agent under certain conditions, may have caused the antioxidative activity (Sapers, 1993). During the preparation of the coating material, the mixture was heated at $90^{\circ} \mathrm{C}$ for 30 min resulting in the formation of intermolecular disulfide and hydrophobic bonds and producing Maillard reaction products (MRPs) that may possess antioxidant activity (Shon and Haque, 2007). The increase in antioxidative activity was likely due to an increase, exposure of free radical scavenging amino acid residues, since heating increased sulfhydryl exposure and peroxyl radical scavenging capacity, but decreased iron chelation capacity (Elias and McClements, 2007; Elias et al., 2006). Skin gelatin hydrolysates from hoki fish (Mendis et al., 2005) and Alaska Pollock (Kim et al., 2001) skin have demonstrated noticeable free-radical scavenging activity and linoleic acid peroxidation inhibition.

\section{Percent moisture loss (PML)}

The storage time was found to have a significant effect on moisture content (MC), while the interaction of treatment and storage time was also significant $(p<0.05)$ (Table 3). The mean initial MC was $76.2 \pm 0.56$ and $75.8 \pm 0.54 \%$ for the control and gelatin-coated sausages, respectively, during refrigerated storage (Table 3). Initial MC decreased to a final $\mathrm{MC}$ of $67.3 \pm 0.41$ and $69.9 \pm 0.37 \%$ for the control and gelatin-coated sausages, respectively. This reflected a 11.7 and $7.85 \%$ loss of moisture for the control and gelatin-coated sausages, respectively, during the experimental period.

The PML was greatly affected by the change of moisture content in sausages during refrigerated storage. The storage time was found to have a significant effect on PML, while the interaction of treatment and storage time was also significant $(p<0.05)$ (Table 3$)$. The PML for both control and gelatin-coated sausages increased with increased storage period. There was a significant effect in PML of gelatin-coated sausages compared to the control sausages after $2 \mathrm{wk}$ of storage period $(p<0.05)$ (Table 3 ). The PML was $3.94 \pm 0.47$ and $3.17 \pm 0.52 \%$ after the first wk of storage and then continued to increase to $11.7 \pm 0.81$ and $7.85 \pm 0.72 \%$ for the control and gelatin-coated sausages at the end of storage. The control sausages were less protected with PML values of $11.7 \pm 0.81$ compared to $7.85 \pm 0.72 \%$ for the gelatin-coated sausages. Thus, gelatin-coated sausages had less moisture loss than the control. A significant reduction of PML by $32.6 \%$ over the 
Table 3. Moisture contents and percent moisture loss of sausages with gelatin-based edible coating during storage at $4^{\circ} \mathrm{C}$ for 8 wk under vacuum package

\begin{tabular}{cccccccc}
\hline \hline & & \multicolumn{6}{c}{ Storage time (wk) } \\
\cline { 3 - 8 } & & 0 & 1 & 2 & 4 & 6 & 8 \\
\hline \multirow{2}{*}{ MC (\%) } & Control & $76.2 \pm 0.56^{\mathrm{a}}$ & $73.2 \pm 0.54^{\mathrm{b}}$ & $70.9 \pm 0.76^{\mathrm{cY}}$ & $68.8 \pm 0.47^{\mathrm{dY}}$ & $67.6 \pm 0.42^{\mathrm{eY}}$ & $67.3 \pm 0.41^{\mathrm{eY}}$ \\
& Gelatin & $75.8 \pm 0.43^{\mathrm{a}}$ & $73.4 \pm 0.23^{\mathrm{b}}$ & $72.2 \pm 0.57^{\mathrm{cX}}$ & $70.8 \pm 0.42^{\mathrm{dX}}$ & $70.3 \pm 0.36^{\mathrm{dX}}$ & $69.9 \pm 0.37^{\mathrm{dX}}$ \\
\hline \multirow{2}{*}{ PML (\%) } & Control & - & $3.94 \pm 0.47^{\mathrm{d}}$ & $6.96 \pm 0.57^{\mathrm{cX}}$ & $9.71 \pm 0.66^{\mathrm{bX}}$ & $11.3 \pm 0.73^{\mathrm{aX}}$ & $11.7 \pm 0.81^{\mathrm{aX}}$ \\
& Gelatin & - & $3.17 \pm 0.52^{\mathrm{d}}$ & $4.75 \pm 0.62^{\mathrm{cY}}$ & $6.54 \pm 0.74^{\mathrm{bY}}$ & $7.30 \pm 0.69^{\mathrm{abY}}$ & $7.85 \pm 0.72^{\mathrm{aY}}$ \\
\hline
\end{tabular}

${ }^{1)}$ Values represent means of 3 replications \pm SD.

${ }^{\mathrm{a}-\mathrm{d}}$ Means within the same row with different superscripts are significantly different $(p<0.05)$.

${ }^{\mathrm{X}, \mathrm{Y}}$ Means within the same column with different superscripts are significantly different $(p<0.05)$.

Control, uncoated sausage; gelatin, gelatin coated sausage; MC, moisture content (\%); PML, percent moisture loss (\%)

control was achieved by gelatin coating at the end of storage. This may be attributed to the good moisture-barrier properties of gelatin coating. Previous reports demonstrated that whey protein coating reduced the moisture loss in cut LFSs (Shon and Chin, 2008) and cut beef steak (Haque et al., 2009). During the preparation of the coating solution, the mixture is heated at $90^{\circ} \mathrm{C}$ for $30 \mathrm{~min}$, producing disulfide bonds and greater surface hydrophobicity (Shon and Haque, 2007). It is conceivable that the gelatin coating was effective as a moisture-barrier because of its hydrophobic nature (Shon and Haque, 2007). Data indicate that calcium chloride incorporated into the coating solution improved the moisture-barrier properties of gelatin films. Protein-based edible coatings containing calcium salts, which are as a cross-linking agent, have the potential to increased hydrophobicity (Park et al., 2001) and decrease water vapor permeability in cut Korean beef (Shon et al., 2010) and fresh-cut vegetables and fruit (Shon and Haque, 2007). In addition, the coating mixture was homogenized for $2 \mathrm{~min}$ in a high-shear probe mixer, resulting in the formation of oil-in-water emulsion. Therefore, good emulsifying ability of the proteins correlated with surface hydrophobicity and contributed to improve the moisture-barrier (Shon and Haque, 2007).

\section{Microbial counts}

The effect of gelatin edible coating on microbial growth in sausages was determined over the 8-wk of storage periods at $4^{\circ} \mathrm{C}$ under vacuum package (Fig. 3). As shown in Fig. 3, the total aerobic bacteria (TPC) were approximately $3.23 \pm 0.31$ and $3.27 \pm 0.24 \log \mathrm{CFU} / \mathrm{g}$ for the control and gelatin-coated sausages, respectively, at the beginning of the storage period. A significant linear increase in the TPC was observed as storage time increased for both control and gelatin-coated sausages during refrigerated storage (Fig. 3). The TPC progressively reach to $7.38 \pm 0.27$ and $7.08 \pm 0.24 \log \mathrm{CFU} / \mathrm{g}$ for control and for

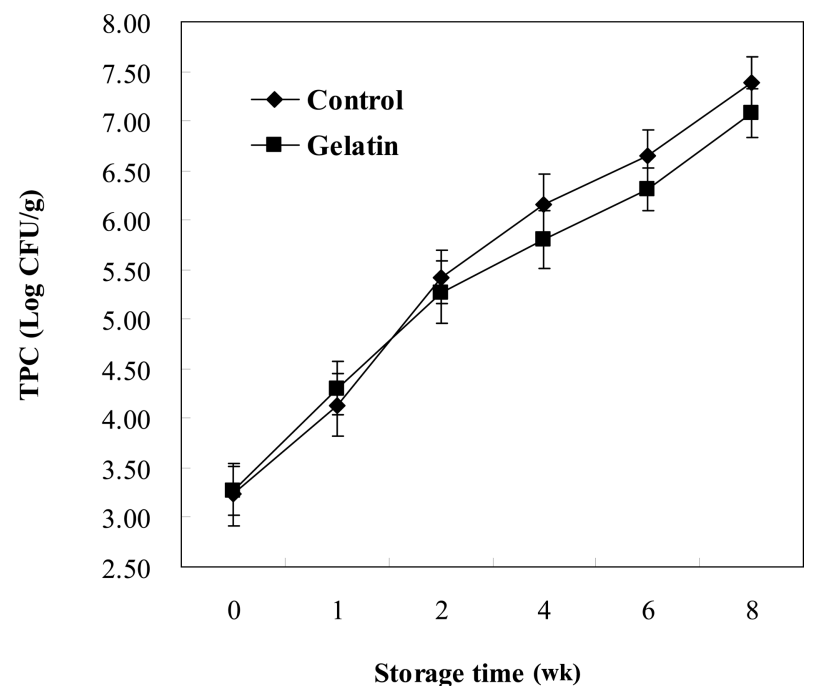

Fig. 3. Microbial changes (total aerobic bacteria) (Log CFU/ g) of sausages coated with gelatin during storage at $4^{\circ} \mathrm{C}$ for 8 wk under vacuum package. Control, uncoated sausage; gelatin, gelatin coated sausage

gelatin-coated sausages, respectively, at the end of the refrigerated storage period (Fig. 3). However, no differences in TPC were observed between control and gelatincoated sausages. These results indicated that the gelatin coating on LFSs was not effective by itself in inhibiting the growth of TPC. A previous report indicated that offodor and slime starts when the total viable counts on meat tissue exceed $\log 10^{7} / \mathrm{g}$ (Verma and Sahoo, 2000). Therefore, sausages may develop off flavors on spoilage with increased storage, and the gelatin coating did not inhibit the microbial growth. Approximately 8-wk was required to reach total bacterial counts of $7 \log \mathrm{CFU} / \mathrm{g}$ in both the control and gelatin-coated sausages.

The effect of gelatin edible coating on the L. monocytogenes in LFSs over the 8-wk of storage period at $4^{\circ} \mathrm{C}$ under vacuum package is shown in Fig. 4. The storage time had a significant effect on L. monocytogenes, while the gelatin coating did not affect the microbial growth 
(Fig. 4). The initial inoculated level of L. monocytogenes in the sausages was around $10^{3} \mathrm{CFU} / \mathrm{g}$. The L. monocytogenes populations also increased from $2.92 \pm 0.23$ and $3.04 \pm 0.22 \log \mathrm{CFU} / \mathrm{g}$ at the initial storage to $6.59 \pm 0.28$ and $6.15 \pm 0.16 \log \mathrm{CFU} / \mathrm{g}$ at the end of the storage time for control and gelatin-coated sausages, respectively (Fig. 4). The slight differences in the initial populations of $L$. monocytogenes might be due to differences in the attachment of bacteria to sausage surfaces. The gelatin coating alone had no inhibitory effect on the growth of L. monocytogenes. Data indicates that both TPC and L. monocytogenes counts were not reduced by gelatin coating alone compared to the control during refrigerated storage under vacuum packaging. A previous report indicated that gelatin and a metaphosphate polymer (Keil et al., 1960) as coatings on processed meats such as sausages, Canadian bacon and boned hams were reduced mould growth and lipid oxidation.

Edible antimicrobial coatings and films are one of the approaches to control contamination of pathogens on the surface of meats and meat products. In other case, whey protein films containing sorbic acid or $p$-aminobenzoic acid inhibited the growth of L. monocytogenes on bologna and summer sausages (Cagri et al., 2002). The SPI hydrolysates incorporated into frankfurters also extended the shelf life of products stored aerobically at $25^{\circ} \mathrm{C}$ (VallejoCordoba et al., 1987). Thus, incorporation of antimicrobial compounds and hydrolysates into gelatin coatings or films may provide synergistic or additional safety and shelf life for RTE meats and meat products.

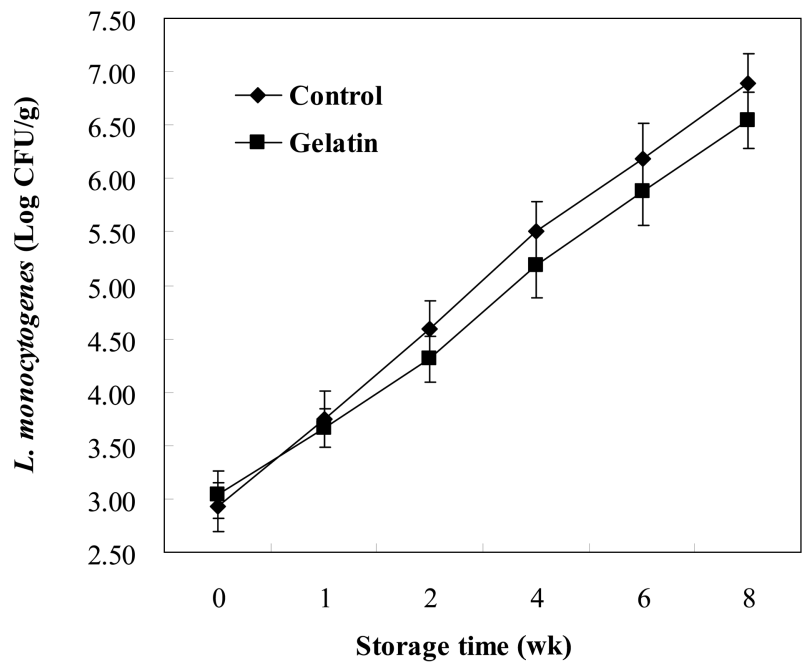

Fig. 4. Microbial changes (Listeria monocytogenes) (Log CFU /g) of sausages coated with gelatin during storage at $4^{\circ} \mathrm{C}$ for 8 wk under vacuum package. Control, uncoated sausage; gelatin, gelatin coated sausage
In conclusion, gelatin edible coating delayed oxidation of sausages as reflected by TBARS and PV. The inhibition of TBARS and PV, as compared to the control, was 21.5 and $26.5 \%$ for gelatin coated sausages. The PML of the sausages was significantly reduced by $32.6 \%$ with gelatin coating compared to the controls. However, gelatin coating on sausages was not effective to inhibit the growth of total aerobic bacteria and L. monocytogenes. The results of this study suggested that gelatin coating used in this study was capable of acting as a natural antioxidative and moisture-barrier coating to retard the lipid oxidation of sausages packed vacuumed during refrigerated storage.

\section{References}

1. Andersen, L. (1995) Biopreservation with FloraCarn L-2. Fleischwirtschaft 75, 1327-1329.

2. Antara, N. S., Sujava, I. N., Yokto, A., Asano, K., and Tomito, F. (2004) Effects of indigenous starter cultures on the microbial and physicochemical characteristics of Urutan, a Balinese fermented sausage. J. Biosci. Bioeng. 98, 92-988.

3. AOAC (1990) Official methods of analysis. 15th ed, Association of Official Analytical Chemists, Washington, DC.

4. Avena-Bustillos, R. J., Olsen, C. W., Olson, D. A., Chiou, B., Yee, E., and Bechtel, P. J. (2006) Water vapor permeability of mammalian and fish gelatin films. J. Food Sci. 71, 202-207.

5. Cagri, A., Ustunol, Z., and Ryser, E. T. (2002) Inhibition of three pathogens on bologna and summer sausage using antimicrobial edible films. J. Food Sci. 67, 2317-2324.

6. Decker, E. A. (1998) Antioxidant mechanisms. In: Food lipids: chemistry, nutrition and biotechnology. Akoh, C. C. and Min, D. B. (eds) Marcel Dekker, NY, pp. 397-421.

7. Elias, R. J., Bridgewater, J. D., Vachet, R. W., Waraho, T., McClements, D. J., and Decker, E. A. (2006) Antioxidant mechanisms of enzymatic hydrolysates of $\beta$-lactoglobulin in food lipid dispersions. J. Agric. Food Chem. 54, 9565-9572.

8. Elias, R. J., McClements, D. J., and Decker, E. A. (2007) Impact of thermal processing on the antioxidant mechanisms of continuous phase $\beta$-lactoglobulin in oil-in-water emulsions. Food Chem. 104, 1402-1409.

9. Elias, R. J., Kellerbys, S. S., and Decker, E. A. (2008) Antioxidant activity of proteins and peptides. Crit. Rev. Food. Sci. Nutr. 48, 430-441.

10. Garcia-Esteban, M., Ansorena, D., and Astiasaran, I. (2004) Comparison of modified atmosphere packaging and vacuum packaging for long period storage of dry-cure ham; effect on color, texture and microbiological quality. Meat Sci. 67, 5763.

11. Gennadios, A., Hanna, M. A., and Kurth, L. B. (1997) Application of edible coatings on meats, poultry and seafoods: a review. Lebensm. Wiss. Technol. 30, 337-350.

12. Georgantelis, D., Ambrosiadis, I., Katikou, P., Blekas, G., and Georgakis, S. A. (2007) Effect of rosemary extract, chitosan and $\alpha$-tocopherol on microbiological parameters and 
lipid oxidation of fresh pork sausages stored at $4^{\circ} \mathrm{C}$. Meat Sci. 76, 172-181.

13. Gray, J. I. and Pearson, A. M. (1987) Rancidity and warmedover flavor. In: Advances in meat research. Pearson, A. M. and Dutson, T. R. (eds) Van Nostrand Reinhold Co, NY, pp. 221-269.

14. Haque, Z. U., Shon, J., and Williams, J. B. (2009) Efficacy of sour whey as a shelf-life enhancer: Use in antioxidative edible coatings of beef steak. J. Food Quality 32, 381-397.

15. Hinterwaldner, R. (1977) Raw materials. In: The science and technology of gelatin. Ward, A. G. and Courts, A. (eds) Academic Press, NY, pp. 295-314.

16. Hur, S.J., Ye, B. W., Lee, J. L., Ha, Y. L., Park, G. B., and Joo, S. T. (2004). Effects of conjugated linoleic acid on color and lipid oxidation of beef patties during cold storage. Meat Sci. 66, 771-775.

17. Keil, H. L., Hagen, R. F., and Flaws, R. W. (1960) Coating composition, method of applying same to a food and coated food product. US Patent 2, 953, 462.

18. Kim, S. E., Kim, Y. T., Byun, H. G., Nam, K. S., Joo, D. S., and Shahidi, F. (2001) Isolation of characterization of antioxdative peptides from gelatin hydrolysate of Alaska pollack skin. J. Agric. Food Chem. 49, 1984-1989.

19. Klose, A. A., Mecchi, E. P., and Hanson, H. L. (1952) Use of antioxidants in the frozen storage of turkeys. Food Technol. 6, 308-311.

20. Krochta, J. M. and De Mulder-Johnston, C. (1997) Edible and biodegradable polymer lms: challenges and opportunities. Food Technol. 51, 61-74.

21. Liu, H. Y., Ding, L., and Guo, S. D. (2008) Extraction and properties of gelatin from channel catfish (Ictalurus punctaus) skin. Lebensm. Wiss. Technol. 41, 414-419.

22. Love, J. D. (1988) Sensory analysis of warmed-over flavor in meat. Food Technol. 42, 140-143.

23. Marggrander, K. and Hofmann, K. (1997) Reduction of freezer burn and loss on drying during long term storage of pork with gelatin spray solution. Fleischwirtschaft 77, 19-20.

24. Mendis, E., Rajapakse, N., Byun, H. G., and Kim, S. K. (2005) Investigation of jumbo squid (Dosidicus gigas) skin gelatin peptides for their in vitro antioxidant effects. Life Sci. 70, 2166-2178.

25. Moerck, K. E. and Ball, H. R. (1974) Lipid autoxidation in mechanically deboned chicken meat. J. Food Sci. 39, 876879.

26. Papastamatiou, F., Gerasopoulos, D., Siomos, A., and Blou- kas, J. G. (2007) Effect of degree of cutting of leek on physicochemical characteristics of Greek traditional sausages. Meat Sci. 75, 648-654.

27. Park, S. K., Rhee, C. O., Bae, D. H., and Hettiachchy, N. S. (2001) Mechanical properties and water-vapor permeability of soy-protein films affected by calcium salts and gluconodelta-lactone. J. Agric. Food Chem. 49, 2308-2312.

28. Sapers, G. M. (1993) Browning of foods: Control by sulfites, antioxidants and other means. Food Technol. 47, 75-84.

29. SAS (2001) SAS/STAT Software for PC. Release 8.1, SAS Institute Inc., Cary, NC, USA.

30. Shahidi, M., Janitha, P. K., and Wanasundara, P. D. (1992). Phenolic antioxidants. CRC Crit. Rev. Food Sci Nutr. 32, 67103.

31. Shon, J. and Chin, K. B. (2008) Effect of whey protein coating on quality attributes of low-fat, aerobically packaged sausage during refrigerated storage. J. Food Sci. 73, C469473.

32. Shon, J., Eo, J. H., and Eun, J. B. (2010) Effect of soy protein isolate coating on quality attributes of cut raw Han-Woo (Korean cow) beef, aerobically packaged and held refrigerated. J. Food Quality 33, 42-60.

33. Shon, J., Eo, J.-H., Hwang, S.-J., and Eun, J.-B. (2011) The effect of processing conditions on functional properties of collagen powder from skate Raja kenojei skins. Food Sci. Biotechnol. 20, 99-106.

34. Shon, J. and Haque, Z. U. (2007) Efficacy of sour whey as a shelf-life enhancer: Use in antioxidative edible coatings of cut vegetables and fruit. J. Food Quality 30, 581-593.

35. Verma, S. P. and Sahoo, J. (2000) Improvement in the quality of ground chevron during refrigerated storage by tocopherol acetate pre-blending. Meat Sci. 56, 403-413.

36. Vallejo-Cordoba, B., Nakai, S., Powrie, W. D., and Beveridge, T. (1987) Extended shelf life of frankfurters and fish frankfurter-analogs with added soy protein hydrolysates. $J$. Food Sci. 52, 1133-1136.

37. Villegas, R., O'Connor, T. P., Kerry, J. P., and Buckley, D. J. (1999) Effect of gelatin dip on the oxidative and colour stability of cooked ham and bacon pieces during frozen storage. Int. J. Food Sci. Tech. 34, 385-389.

38. Yin, M. C. and Faustman, C. (1993) The influence of temperature, $\mathrm{pH}$, and phospholipid composition upon the stability of myoglobin and phospholipid: a liposome model. J. Agric. Food Chem. 41, 853-857.

(Received 2011.8.29/Revised 2011.10.17/Accepted 2011.11.9) 